\title{
EL COMERCIO DE LA COCA Y LAS MUJERES INDIAS EN POTOSI DEL S. XVI ${ }^{1}$
}

\author{
Paulina Numhauser Bar-Magen \\ Depto. de História-FFLCH/USP
}

RESUMO: O estudo dos documentos notariais de Potosí no século XVI, comprovam a presença de mulheres indígenas independentes que monopolizaram o rendoso comércio varejista da coca. Estes testemunhos provam como estas mulheres tiveram a capacidade de acumular bens e de investí-los. Nos perguntamos se este fenômeno que assombrou os contemporâneos foi um produto das exigências vitais do sistema minerador ou a permanência de uma estrutura pré-hispana amparada pelos privilégios particulares do lugar?

PALAVRAS-CHAVE: Mulher Índia, coca, Potosí s. XVI.

ABSTRACT: The study of the notarial documents of Potosí at the XVI's century, reveals the presence of independent indian women who monopolized the profitable retail trade of coca. These documents demonstrate how these women had the capacity of acumulating goods as well as the possibility of investing them. We ask whether this phenomenon that astonished the contemporaries was a consequence of the vital requeriments of the mining site or was due to the pre-hispanic social structure sheltered by the particular privileges of the place?

KEYWORDS: Indian women, coca, Potosí s. XVI.

La estrecha relación existente entre el proceso de producción minera y el que se ocupa de aprovisionar el poblado que alberga a sus trabajadores, debe ser contemplada al estudiar la minería en general y el caso de Potosí en particular.

\footnotetext{
${ }^{1}$ Artículo expuesto en el marco del 49 Congreso de Americanistas de Quito, (ICA), bajo el nombre "Formas familiares matriarcales en Potosí del s. XVI?"
}

Asiento que se levantó a las faldas del Cerro Rico, descubierto el año 1545, ubicado a más de 4.000 metros de altura, en un sitio originalmente despoblado, de difícil acceso, árido e inhóspito, en el cual toda provision debio ser llevada por "acarreto".

Estas dos cosas son las minas y el trajín, sin minas no es de ningún provecho aquel Reyno porque no hay cosa en que se pueda sacar para contratar en otro, antes es falto de muchas cosas para 
la conservacion de la vida humana que se traen de otros Reynos y si no se puede sacar sin gente y esta gente no se puede sustentar sin comer y vestir y no se puede proveer esto sin trajín por estar los asientos de minas en tierra frigidísima que todo se lleva de acarreto y este trajín tampoco se puede hazer sin gente... (B.N.M. mss. 3040 , f.10 s.f. ).

Una intensa actividad comercial al minorista o al detalle se desenvolvió en sus mercados, la cual fue dejada mayoritariamente en las manos de las mujeres indias residentes en el lugar.Esta función las transformó en un factor esencial en su funcionamiento, dándoles la oportunidad a las mas hábiles, de acumular fortunas de variada importancia y a la vez adquirir independencia y seguridad personal.

Noticias referentes a su acción en las calles y mercados de Potosí se pueden encontrar con profusión en la documentación notarial conservada en los diferentes archivos regionales.

Testamentos, asientos de trabajo, contratos de compraventa y juicios, dan testimonio de este acerto e introducen un importante elemento a examinar, en relación al discurso construido en torno a la participación indígena dentro del sistema productivo minero permitiendonos al mismo tiempo, observar con cierta nitidéz, el proceso de imposición del cotidiano en este discurso.

El virrey don Francisco de Toledo (1569-1580), por medio de la implementación de una serie de reformas administrativas, sociales y economicas, jugó un papel importante en el proceso de sacar a la Villa de la crisis de producción en que se había sumergido a partir del año 1566, en que el metal baja de calidad, y las vetas se han ahondado hasta el extremo de convertir la explotación en sumamente riesgosa y poco lucrativa.

Introduciendo el proceso de fundición del metal por amalgamación con azogue, y la construcción de un complejo sistema hidráulico a través de represas artificiales de agua, las famosas lagunas de Potosi, destinadas a proveer de agua a los Ingenios de molienda construidos en las márgenes de la Rivera -; a lo cual debemos sumar otra serie de medidas tendien- tes a incrementar el número de la población indígena de la villa, consiguió reactivar la minería del asiento, la cual logró alcanzar niveles de producción nunca antes registrados por la historia mundial.

Por otro lado, las decisiones administrativas que adoptó y que afectaron a la población del lugar, son de gran interés para la comprensión de su obra política y nos permiten observar los tramos más finos de la política real en Indias.

Toledo arrivó a Potosí el año 1573, como parte de su Visita General del Reyno, el fuerte asombro que le provocó el lugar, esta registrado por los relatos de mayor colorido de su correspondencia con el Monarca.

...en este asiento se an permitido a los yndios y a los españoles que ellas salgan a las plazas y mercados a vender todas las cossas de los de aquí y los de las otras provincias ymbian a este asiento y el corregidor que a querido reformar esto le a opuesto que destruie a este asiento, ningun gobernador que lo viese y tocase con las manos se atreveria a poner remedio con las falsas informaciones que desta tierra se da (B.N.M., mss. 3040 f.91v.).

Sus consejeros habían preparado al virrey para el encuentro con las calles del asiento, sin embargo ello no evitó la explosión de profundo asombro que le embargó a medida que se internaba por las callejuelas enrevesadas del lugar, y se ponía en contacto con su heterogénea población indígena.

Del asiento de que aqui no se puede dar enteramente razón del a vuestra magestad que aunque aya mas de tres meses que yo llegué y lo e visto todo por mi persona y puesto visitadores particulares para cada cossa como tengo dicho en la carta de govierno todavia avre menester mas tiempo para entenderlo...(Levillier Gobernantes del Peru 1924 t.V carta del virrey Toledo al Rey Potosí 20 de marzo de 1573).

Este funcionario juzgó que cualquier reforma a adoptar debía incluir un incremento importante del número de habitantes, las medidas que tomó para ello abarcaron el reconocimiento de la costumbre del lugar, desenvuelta desde el comienzo de explotación del 
Cerro, incluyendo tanto al intento por mantener a los indígenas como factor líder en el sistema productivo, (discusión sobre la venta de metal robado por los indios) $)^{2}$, de fundición, (mantenimiento de las guayras) ${ }^{3} \mathrm{y}$ de las medidas de protección del trabajo de las indias del lugar.

El año 1575, en viaje de regreso a Lima, dando por terminada la Visita General, el virrey legisló un conjunto de disposiciones que formaron las Ordenanzas para los Indios de Las Charcas, que incluyeron varios artículos que demuestran que para esa época había terminado de estudiar la realidad de la región, convenciéndose de la importancia del papel de la mujer india como parte del sistema productivo del Reyno en general.

De acuerdo al artículo $\mathrm{V}$, se prohíbe que las niñas indias sean separadas de sus madres para ir a escuchar catecismo, porque su principal obligación es ayudar a sus madres en las labores cotidianas, en el artículo XXXII, se da orden que en los pueblos donde existieren antiguos mercados los indígenas continúen

\footnotetext{
${ }^{2}$ Esta discusión surgió temprano, a medida que la riqueza del metal se iba agotando y los dueños de minas que en un comienzo le restaron importancia comienzan a vigilar los montos de sus ganancias. El momento más álgido se produjo cuando el padre jesuita Francisco Baena comienza a predicar, - azuzado por sus feligreses -, contra el robo de metales y la venta de ellos en el mercado por los indios. El virrey Toledo reaccionó enérgicamente contra estos embates desterrando a Baena y obligando al jefe de la orden Jesuita, en ese momento el padre y cronista, Joseph de Acosta, a desautorizar a su subordinado declarando que los indios tenían derecho a vender libremente el metal.

${ }^{3}$ Las guayras u hornillos de orígen indígena pre-hispano, fueron la solución al problema de la fundición del metal en el asiento, hasta la introducción del proceso de amalgamación por azogue. En ese momento Toledo las conserva y esta politica sustentada sobre las bases de la costumbre del lugar, fue uno de los pilares que posibilitaron que el orden de explotación que estudiamos siguiera funcionando aún después de haber sido implantados los Ingenios de azogue.
}

comprando y vendiendo dos veces por semana, y que donde no hubieren se hagan; en el artículo XIII, se prohibe que los caciques o curacas cobren tributos a las indias casadas y en el XXVI se exige a los Corregidores de Indios que vigilen que los naturales no mueran $a b$ intestato (Levillier Gobernantes del Perú, t.VIII, 1924, p.304-382).

Podemos sostener que Potosí fue construido como un lugar privilegiado por la Corona, la cual basó su política de concesión de mercedes especiales a los asientos mineros en la experiencia acumulada a través de largos siglos de gobierno, en que el principio de reivindicación de la potestad sobre los yacimientos minerales del subsuelo de sus territorios, fue un factor indiscutido por las monarquías europeas. En Castilla y León esto comienza a ser codificado a partir del siglo XIII (COLECCION LEGISLATIVA de MINAS, 1889) (BORRAR, p. 266).

Esta condición especial de la villa ya la observó el historiador J.Lockhart, (1982, p.266); según el cual a pesar de haber sido Potosí un factor altamente importante en el proceso desorganizador de la población indígena, jugó un papel casi nulo como elemento de aculturación, hecho que se tradujo en que la numerosa y abigarrada masa de pobladores indígenas del lugar mantuvo sus costumbres -religión y lengua - a pesar de el estrecho contacto con los europeos. Las expresiones de sorpresa que registró Toledo en su correspondencia reflejan sin dudas el fuerte choque cultural del español con una urbe de características predominantemente indígenas a la cual termina llamando, como lo hicieron antes y despues de él muchos otros españoles, la Babilonia de Indias.

Respondiendo a las leyes de la oferta y la demanda los mercados potosinos se repletaron de productos de consumo exigidos por los naturales, poseedores de

\footnotetext{
${ }^{4}$ Hasta la crisis de producción de mediados de la década del 60', diversos testimonios documentales coinciden en presenta $\mathrm{r}$ la
} 
un enorme poder adquisitivo, adquirido como resultado del sistema de explotación adoptado desde el comienzo de la mineración en el Cerro Rico ${ }^{4}$.

Artículos de primera necesidad arribaron incesantemente al lugar, incluyendo desde los Andes del Cuzco, la preciada yerba coca, la cual fue comerciada al minorista con grandes márgenes de ganancia por las mujeres indias, que desde los inicios del asiento comienzan a ser señaladas en la documentación notarial como las indias de la calle de la coca o las indias coqueras.

La mujer india como elemento social integrado al medio urbano ha sido poco estudiado, sobre todo durante el período temprano de la colonización. Entre las excepciones se cuentan los estudios sobre testamentos de finales del siglo XVI en Quito, de Frank Salomon (1988, p.325-341), y para el mismo período en Arequipa por Elinor C.Burkett (1978, p.118 ).

Sin embargo estos trabajos o por la escacéz del material documental con que contaron, o por haber tratado el tema de acuerdo a la selección arbitraria de un solo tipo de documentos, testamentos en el caso de Salomon, no lograron abarcar de manera integral a estas mujeres.

Esto no es lo que acontece con las indias de la calle de la coca de la Villa Imperial, las cuales por la importancia y complejidad de su accion económica, que las puso en contacto con una pluralidad de factores

versión de acuerdo a la cual la riqueza del metal y la facilidad de extraerlo hizo que los dueños de las minas abandonaran su explotación en manos de sus yanaconas o indios varas, quienes ponían los materiales de expotación, entregando la cacilla o yema, la parte más rica del metal extraído, al dueño de la mina, restándole al indio el metal sobrante. Esta version referente a la forma de explotación del mineral en el período temprano de Potosí, se puede consultar en la B.N.M.el mss.3040, la cual es ratificada por el cronista Luis Capoche (1959, p.108-11). Sin embargo estas interpretaciónes deben de ser cotejadas con documentos alternativos y que presenten la version contraria, ver, A.G.I. Justicia 677. sociales, dejaron rastros definidos en la documentación notarial del período, incluso sobre su vida privada.

Por otro lado, no obstante que la documentacion notarial, da la sensación de confiabilidad, debe ser analizada con sumo cuidado, pues tanto ayer como hoy, existieron individuos prontos a prestar testimonios falsos a un notario, y tanto entonces como ahora, muchos cayeron en sus redes. Un historiador debe de la misma manera aproximarse con espíritu crítico y recelo a toda la documentación con que trabaja.

De manera que si bien los testamentos de indias, que por un lado nos presentan datos de sumo interés referentes a los bienes acumulados durante la vida productiva de estas mujeres y sobre sus relaciones de trabajo y medio que las rodeaba, pueden esconder al mismo tiempo, graves distorciones que los convierten en un testimonio mucho menos seguro en lo referente a los restantes datos que contienen.Cada testamento e incluso documento de compraventa o de otro tipo, puede esconder entre sus líneas un intrincado drama personal, frente al cual debemos estar alertas.

El año 1588, el monarca ordenó al Conde del Villar, (Fernando de Torres y Portugal, 1584-1588), su virrey en el Peru, que en vista que se ha enterado de las graves irregularidades que suelen acontecer estando un indio rico enfermo y

...le va a confesar un religioso o clérigo a cuyo cargo esta su doctrina, y procura y da orden como haga testamento y que en el dexe a él o a la Iglesia toda o la mayor parte de su hazienda, aunque tengan herederos forzosos, y que con los Indios ladinos sacristanes, que tienen en las dichas Yglesias, que por la mayor parte son criados suyos embian a hazer prevenciones con los dichos enfermos, y aquellos se persuaden en ello, y que cuando la justicia lo viene a entender ya el difunto esta enterrado, y el cura o la Yglesia apoderados de la hazienda, y por este camino quedan muchos pobres defraudados de las herencias que les pertenecen... (ENCINAS, v. II, 1945, p.166-167).

En realidad, a oidos del Rey y su Consejo de Indias hacía tiempo que estaban llegando quejas so- 
bre este grave abuso, el que por lo demás, fue muy difícil de erradicar.

De manera que algunos años después, el Cabildo de los Veinticuatro de Potosí, se ocupó también del tema, y en las Instrucciones que despacha a su procurador en la Corte, Luis Dávalos de Avila, le solicita que se queje porque

...los curas de las parroquias de la dicha villa quando algun indio muere le consumen todos los bienes que dexan, unos porque ellos mesmos les hazen los testamentos e se dexan en ellos por herederos y otros a titulo de que se les deve dar el entierro y de las andas e cruz alta desde la casa del muerto a la Yglesia quitando a sus hijos e padres la legítima que se les debe de derecho natural...(A.N.B. ACTAS DEL CABILDO DE POTOSI, t.8, f.10).

Entre las escrituras notariales, se encuentran varios documentos que corroboran estas preocupaciones de las autoridades.

El mismo año 1588, en que el Monarca despacha el decreto anteriormente citado, Francisca Chimpo Ocllo, palla o india noble, natural del Cuzco, cuyo estatus de india casada y velada segun la orden de la Santa Madre Iglesia, es poco común entre las mujeres comerciantes de Potosi, dictó su testamento.

Su marido la abandonó hace catorce años aproximadamente, yéndose a vivir a la ciudad de Tarixa, desde donde a veces a acudido a verme y hablarme, los bienes acumulados por este matrimonio y que han sido ganados por ambos a dos y por ende deberán ser repartidos equitativamente al momento de disolución del vínculo, preocupan a Francisca por que las casas,...que al presente bibo que las he ganado y edificado con mi sudor y trabajo queden de la parte de los dichos bienes myos...y a pesar de que con ella vive María india, al parecer una criada, y a quien le deja de herencia 30 pesos corrientes y un luto, cómo de acuerdo al documento parece que no tiene heredero alguno a quien dejar sus propiedades, decide destinarlas para

...meter a monja a una española o montañera pobre $y$ necesitada la qual sea la que le pareciere a mys albaceas la qual dicha casa le doy porque rueguen todos por my anyma... agregando además que mientras esta montañera no se encuentre sus albaceas, un clérigo llamado Lima y un español de nombre Benyto Peñalosa, deberán ser los encargados de repartir el arriendo de acuerdo a su parecer, en rogativas por su alma y en limosnas por el rescate de los cautivos (C.M.P.,1588, e.n.13).

Si bien este testamento concuerda con las denuncias referentes a dolo, nos presenta otro problema que debe de ser tomado en consideración al estudiar este tipo de testimonios, la ausencia de herederos o la dificultad para encontrarlos pudo haber sido también una consecuencia del carácter de inmigrantes de la población que se estableció en el asiento.

Este problema preocupó al virrey el cual determinó que en caso que alguien no poseyera susesores directos debía de ser heredado por sus ascendientes próximos, lo que regía en todos los territorios bajo dominio de la Corona castellana, desde que se promulgaron las Leyes de Toro, (MARTÍNEZALCUBILLAS, 1885, p.719-128), el año 1505 , y que rigieron por derecho de prelacía en todo el reino en lo que se refiere a materia de derecho civil. Sin embargo, Toledo atribuyéndose la prerrogativa de $e x$ plicar este Código de acuerdo a las necesidades de Indias, ordenó que

...a falta de hijos no excedan las mandas que hicieren a otras personas, y por su ánima, de la mitad de los bienes que dejare, porque la otra mitad la hayen libre los herederos por ser forzosos...(LEVILLIER, t.VIII, 1924, p.326).

Evidentemente los testamentos carentes de herederos son una minoría, que ya Frank Salomon (1988, p.328), calculó en un $43 \%$ para Quito a finales del siglo XVI, aunque la posibilidad de llegar a establecer cualquier tipo de cálculo estadístico a través de estos testimonios, resulta muy peligroso, aun más si aceptamos la posibilidad de engaño denunciados por las autoridades de entonces y por las vivas sospechas que surgen al estudiar su contenido. 
Los distintos problemas referentes al empleo de escrituras notariales por la historiografía ha sido tratada en detalle por Adelaine Daumard y Fraçoit Furet (1959, p.676-693).

No podemos descartar, sin embargo, la posibilidad de desenvolver una pesquisa que permita acercarnos a las vidas privadas de estas mujeres indias, reconstruyendo en lo posible su entorno familiar y social, en base a las secciones más confiables de esta documentación, las que incluyen en los testamentos un recuento pormenorizado de los debes y haberes que lograron acumular durante su vida de trabajo, sus acciones ante la justicia de la villa y el numero abundante de contratos de compraventa efectuados entre indios, que nos permiten comprobar que el objeto de mayor interés en que invirtieron sus ahorros fue en la compra de bienes raíces del lugar.

El instante de celebración del contrato de compraventa debía de realizarse ante un notario, exigiéndose también la presencia del Justicia Mayor, del Corregidor de Indios o del Alcalde Mayor de Potosi, debiendo además comparecer, de acuerdo a las Leyes de Toro, el marido en caso de existir tal, dando su consentimiento a la acción de su mujer.

En la Casa de Moneda de Potosí, se conservan variados tipos de contratos de compraventa efectuados entre indios en general y en particular entre las mismas mujeres coqueras.

El 12 de enero de 1572, comparecieron ante el escribano público Martín de Barrientos y de don Diego de Gamarra Alcalde Ordinario, Catalina natural ynga, junto a su marido, Hernando Santón, natural chachapoyas, la cual declara que

de buena voluntad vende y da cuenta a Elvira Mañy, india, presente una casa que tiene en esta villa detrás de las carnicerías que lindan con las casas de esta parte y por la otra con las casas de Ysabel, india, criada de Antonio de Vargas, la qual dicha casa ay tres bohíos y cercas con pertenencias entradas y salidas, pertenencias usos derechos y costumbres y servidumbres... por la cuantía de 200 pesos de plata corriente (C.M.P., 1572, e.n.4, f.22).
La adquisición de propiedades fue un acto de gran importancia para estas mujeres no solamente como una forma de inversión, de una cantidad relativamente importante de capital, sino por su significado cultural que pudo estar relacionado con la tendencia que se observa en algunos de estos testimonios de transmisión del bien por vía materna.

En una fecha cercana a la del contrato anteriormente citado, otra mujer llamada Catalina Palla, oriunda del Cuzco, dictó su última voluntad, por intermedio del mestizo, Juan de la Peña, quien sirvió de lengua, junto a su lecho de enferma se encontraban además sus dos hijas, Francisca niña de catorce años, y María de Balencia hija de una unión previa con Pedro de Balencia de la ciudad de Arequipa, también estubo presente su $\mathrm{amo}^{5}$, término con que se refiere a su conviviente y padre de su hija menor, Gregorio de la Peña.

Catalina que se dedica a la venta de coca y pan, a logrado reunir un capital de trabajo que le permite mantener a sus hijas, la participación en estas ganancias de Gregorio no queda clara, sin embargo la relación entre los miembros de este grupo familiar, parece haber estado fuertemente determinada por el peso de la presencia de este último, el cual es nombrado albacea, imponiéndo sus valores e intereses por sobre los de Catalina, tensión que se observa claramente en el documento.

Declaro que Gregorio de la Peña mi amo me hizo donación y a mis hijas destas casas y corrales que al presente moro para que durante los dias de mi vida y de las de mis hijas viviese en ellas, e las tubiere e gozase como de cosa mia propia, digo y declaro

\footnotetext{
${ }^{5}$ La relación existente entre un amo y su criada o criado, que tiene connotaciones que lo relacionan al vínculo de yanaconaje, fue comúnente empleada en este período, abarcando toda la gama de relacionamientos entre un europeo y un indio no mitayo, relacionado a él temporalmente sobre la base de un asiento de trabajo asalariado e incluso a relaciones entre indios, sobre lo cual se conservan numerosos documentos.
} 
que las dichas casas y corrales de que ansi me tiene hechas la dicha donación de ques de los dias de mi vida son del dicho Gregorio de la Pena y de las dichas mis hijas y de Juan de la Peña hijo del dicho Gregorio de la Peña y en esto me remito a la dicha donación...De esta manera las casas terminan convirtiendose también en propiedad de este último, y la hija de Pedro de Balencia que según su madre es propietaria como su hermana del bien raíz, se decide que si el dicho su padre la quisiere llevar se la de el Gregorio de la Peña.

Nombra como sus herederos universales a Juan y a su hija Francisca poniendo fuera a su hija María a quien le deja tan sólo la suma de cincuenta pesos de plata corriente como dote, $y$ con esto la aparte de todos mis bienes y herencia (C.M.P., 1572, e.n.6 f. 51 y ss.).

El acto jurídico de donar ${ }^{6}$, fue muy empleado en Potosi, en las relaciones de yanaconaje entre las criadas de los comerciantes de coca y sus amos los cuales como una forma de agradecimiento y recompensa, les donaron bienes raíces. Las donatio propter nupcias, que son las que corresponden en este caso fueron equivalentes a las dotes, pues no volvían al esposo o donador en caso de sobrevivir éste a la mujer, sino que fueron reputados como bienes traspasables a los herederos directos de la mujer. Por lo cual resulta evidente que por sobre la ley y la última voluntad de Catalina se imponen los intereses de su amo, hecho que particulariza este caso, pues generalmente fueron las mujeres las que sobrevivieron a sus compañeros.

\footnotetext{
${ }^{6}$ Donación propter nuptias o ante nuptias, en su orígen fueron donaciones hechas a la mujer en vísperas de su casamiento por su futuro marido o por un tercero, la intención de ésto fue evidentemente el establecimiento de la igualdad entre los cónyugues, ésta costumbre alcanza su máximo desenvolvimiénto en la época tardía del Derecho Romano, ver, PETIT, 1972, p.568-569. En las Leyes de Toro se acuerda que en el caso de las donaciones débese atener a la Ley del Fuero, que permitía solamente en caso de tener alguien heredero legítimo hacer donación de hasta la quinta parte de sus bienes.
}

La tendencia hacia el mantenimiento de una sociedad indígena bi-líneal en que la sucesión se establece por línea materna o paterna separadamente, de acuerdo a un posible orden pre-hispano y que pareciera notarse en algunos de estos testimonios, resulta no obstante difusa y posiblemente fue asimilada por la estructura paternalista del documento testamentario a través del cual estudiamos el fenómeno.

Los testamentos incluyeron entre las listas pormenorizadas de los bienes de estas mujeres, su vestuario y joyas, datos que nos permite reconstruir la forma como estas ricas comerciantes se engalanaban cotidianamente, siendo posible comprobar que sus prendas continuaron siendo las tradicionales, y que a medida que su riqueza se incrementaba, ellas se preocuparon por hacerlo patente en su apariencia personal.

Francisca Carna, poderosa mujer coquera al mayorista, entre sus alhajas cuenta con cinco pares de topos con sus cadenas de plata.

Algunos han pretendido que el cuidado de estas mujeres por su vestuario tuvo importancia ritual y que el traspaso de estos artículos a sus hijas, comprueba la tesis de una sociedad matriarcal, sin embargo, en la misma medida en que estas mujeres transmitieron su vestuario a sus herederas por razones obvias, los padres de los niños naturales nacidos de las uniones con ellas, al dictar sus testamentos tambien donaron a sus hijos varones el suyo, evidentemente no podemos desconocer el alto valor económico que tuvieron estos artículos de primera necesidad.

De acuerdo a Elinor C. Burkett, la cual pesquisó la documentación de notarios del primer período de la ciudad de Arequipa, la cantidad de estos testimonios originados por mujeres indias es muchísimo mayor que los registros sobrevivientes de varones, según opina esta historiadora, esto fue originado por el papel diferente que la naciente sociedad colonial les dio a cada uno de los sexos, siendo la mujer la que pudo con mayor facilidad penetrar en la vida domestica europea como en otras ocupaciones, ayudada por 
el hecho que inspiró un mayor nivel de confianza que su compañero, menos dócil.

Lo que se pretende sustentar detrás de esta observación es la tesis que la mujer indígena se ladinizó en un grado superior a los varones, hecho fácil de comprobar, según Burkett, por el nivel superior de su participación en la documentación de notarios, y que en la vida urbana diaria se tradujo, en una separación radical entre los sexos llevando ambos grupos vidas sociales y productivas separadas (BURKETT, 1978, p.118).

Evidentemente esto no aconteció en Potosí donde su numerosa población indígena se integró en un esfuerzo mancomunado en el proceso de explotación minera y de supervivencia.

En la misma medida que las mujeres indias subieron cada miércoles alimentos al Cerro para los mineros, varones indios participaron del proceso de aprovisionamiento y en oficios imprescindibles para el funcionamiento de la villa. Las actividades domésticas también ocuparon a indios de acuerdo a los datos que aporta la documentación notarial, pudiendose observar que precisamente fueron los varones los que experimentaron un proceso de ladinización más intenso, siendo ellos los que ejercieron el oficio de lenguas o intérpretes, mimetizándose en la documentación por razón de su vestuario, nombres, lenguaje y las formas europeas de comportamiento que adoptaron.

En la ciudad de La Plata, el año 1569, Luis de Aldana,

indio, sastre (ladino vestido en ávito de español), morador de ésta ciudad...declaró que,...devo e me obligo a dar y pagar realmente en efecto a Magdalena, yndia natural canari ques presente...ciento y treynta e siete pesos de plata corriente a cuatro pesos el marco, los que a vos debo e son por razon que por me hazer buena obra me prestastes otros tantos pesos de plata..., dejando como garantía su casa,...porque seais mas segura desta deuda como cosa que tan bien devida, vos ypoteco por especial obligación e ypoteca, noviciando ni denegando la general a la paga y seguridad desta deuda vos empeño e ypoteco, no viciando ni derogando la general a la paga y seguridad desta deuda vos enpeño e ypoteco un solar con dos bohíos de paja que tengo en esta ciudad quees en las que al presente vivo (A.N.B. e.p. BRAVO f. 1058 y ss.),
La mujer india no solamente trabajó junto al varón sino que poseyendo en el caso de las vendedoras de la coca, una mayor posibilidad de ser retribuidas con salarios más altos que sus compañeros, fue ella la que mantuvo a sus hijos y en muchos casos al padre de ellos tanto si fue español o indígena.

La conclusión a que podemos llegar como resultado de las acciones de estas vendedoras registrados en e stos documentos es que lograron conquistar en base a su actividad comercial una marcada independencia personal.

El importante espacio económico-social que se les abrió a estas mujeres, estubo sustentado por los conceptos económicos escolásticos del período. La actividad comercial a que se dedicaban era llevada adelante entre indios, siendo el comercio entre iguales liberado de engaño o fraude. La coca fue un producto comprado por los naturales y vendido por ellos, a través de un comercio justo

....por no ser de perjuizio, ni poderse aver contra los yndios que son los que las compran porque no puede aver engaño de parte del bendedor no de parte del comprador por ser cosa savida y entendida dellos...(A.N.B., 1595, e.p.1).

De manera que ellas pudieron ejercer sus funciones sin la necesidad de pasar por un proceso de asimilación al medio europeo, movimentándose en su actividad comercial casi esclusivamente en un ambiente cultural indígena, siendo su calidad de indias precisamente el factor que les permitio ejercer su trabajo.

Fueron varios los niveles de actividad que estas mujeres desempeñaron en relación al comercio de la coca.

En primer lugar se ubicaron las criadas de los comerciantes mayorístas o de los factores de estos comerciantes, las cuales en base a una relación de yanaconaje vendían la coca de sus amos en el mercado o calle de la coca o en la tienda convenida, ésta fue la manera como en los inicios de la explotación minera del Cerro, se comenzó la venta de coca en el Gato o tianguéz del lugar. 
Posteriormente estos acuerdos comerciales comenzaron a formalizarse ante notarios por asientos de trabajo, los cuales fueron celebrados por un espacio de tiempo limitado, un año por lo general, con el salario y el resto de las retribuciones cuidadosamente detalladas.

Finalmente se ubicaron las mujeres que comerciaron de manera independiente, las cuales por lo general iniciaron su carrera como criadas de comerciantes europeos mayoristas o de otras mujeres indias y que gracias a su habilidad lograron elevarse en esta actividad al nivel de minoristas independientes y algunas incluso al carácter de mayoristas, las cuales a su vez, se rodearon de criadas indias aprendices que rapidamente pasaban de este nivel al de pequeñas comerciantes de cantidades menores de coca, recomenzando de esta manera el ciclo.

Se puede observar de acuerdo a este análisis que los niveles económicos en que ellas se movimentaron fueron muy variables, estubieron las que compraron pequeñas cantidades de yerba para subir al Cerro y trocarla por trozos de mineral rico para guayras, y existieron las que adquirían dos o tres cestos al fiado para venderlo a su vez de la misma manera, y también las que compraron partidas de decenas de cestos, para comerciarlas desde sus propias tiendas.

Como criadas de un español mayorista estas mujeres pudieron transformarse en la base del negocio de su $a m o$, hasta el extremo de convertirse en imprescindibles. Esta dependencia fue a veces muy marcada, el caso de Sebastián Rodriguez natural de la ciudad de Orense que agregó un codicilo a su testamento el año 1569 otorgándole a Angelina su criada, que esta en mi casa, además del dinero que ya le había legado en el documento anterior, otros cien pesos de plata corriente para su hija Ysabel,

mestiza..., y que se den a Salvador su hijo, [de Angelina], la ropa que yo tubiere a tiempo que falleciere de mi bestir y que asimismo se le de un caballo de los que yo tubiere...

sin embargo, la condición para recibir todos estos bienes es que Angelina y sus hijos acompañen a la mujer de Sebastián, Ynés
Vázquez, hasta tanto se cobren todas las deudas de yndios e yndias porque las conoce y sabe quien son... (A.N.B. BRAVO, 1569 Esc. Pú. 4 f. 1412v. y ss.).

Como el éxito de las ventas dependieron de la capacidad de la mujer vendedora, observamos que los salarios fueron sujetos a negociación y condicionados en gran medida por la experiencia y habilidad de la mujer coquera que celebraba el asiento.

El caso de Leonor Sucama, india natural del pueblo de Caracara, que el 9 de enero de 1571, compareció ante el escribano y el Alcalde Mayor de la villa, acompañada de su marido, con el objeto de declarar que ella

estaba concertada con Diego Hernández morador desta villa para le servir por un año en vender coca en esta villa por razón que le ha de dar por el dicho año cincuenta pesos de plata corriente e tres fanegas de maíz e un vestido de avasca...

Además de los beneficios obligatorios que acompañaban estos contratos, o sea, curarla en caso de enfermedad, catequisarla etc. (C.M.P. MARTIN de BARRIENTOS, Esc.Pú. 4, f.23v. y ss. 1572), se repiten en la documentación y comprueban los altos niveles salariales que podía llegar a recibir una de estas mujeres.

Los precios de los alimentos en el asiento fluctuaron de acuerdo a la oferta y la demanda, de manera por lo general descontrolada, a pesar de los esfuerzos de los cabildantes, manteniéndose por lo general altos, calcúlase que un minero mitayo gastaba solamente en alimentarse un $75 \%$ de su salario ${ }^{7}$, información que ha

\footnotetext{
${ }^{7}$ P. Bakewell, op.cit., p.113. Esta estimación está calculada en base de un informe despachado al rey Felipe III, por Felipe Godoy el año 1608, de acuerdo al cual por un período de trabajo de 26 semanas, retribuido en base a 2,5 pesos por semana, un indio mitayo recibía 65 pesos de salario, de lo cual tenía que extraer 16 pesos por la tasa de medio año, a lo cual debía agregarse 26 pesos por las velas que gastaba en su trabajo, las cuales debían de ser proveídas por el indio minero, además de otros gastos mínimos.
} 
servido para llegar a la conclusión, que fue imposible que con el salario recibido por un indio, del cual debía de extraerse la tasa y otros gastos fijos, se pudiera mantener él y su familia. Este fue el orígen de la suposición de que en Potosí la población indígena deambulaba paupérrima y hambrienta por sus calles.

Para una mujer excenta del pago de la tasa, y con un amplio acceso a variadas fuentes de trabajo la obtención de alimentos podía ser menos dificultosa, por ejemplo, Ysabel Guayco, yndia natural chumvivilcas, con el consentimiento de su marido se presenta ante el escribano del asiento y el Alcalde Ordinario, el dia 4 de noviembre de 1572, declarando que se compromete a encargarse de una tienda de venta de maíz, por lo cual su dueño se obliga a pagarle un sueldo de dieciseis pesos de plata corriente al año además de dos vestidos de avasca y doze cargas de maiz, que en cada un mes una carga y en cada una semana un tomín de plata para comprar carne (C.M.P.,1572, esc. not.4 f.29 y ss.).

Sin embargo, el comercio de la coca al minorista, se desenvolvió mayoritariamente, en base a acuerdos de palabra, en que la confianza mutua fue la que predominó sin que surgiere la necesidad de solicitar a un factor externo que los hiciere respetar. Los recursos al escribano con lo cuales aquí tratamos fueron

A ésto deben sumarse 150 pesos que es su cálculo por alimentación durante este lapso de tiempo, lo que lleva a éste historiador a calcular en 200, 10 pesos los gastos mínimos que se veía obligado a realizar un indio mitayo para su propia manutención durante este período de trabajo, cantidad imposible de cubrir con el salario recibido.

Sin embargo, estos datos deben ser tratados con extremo cuidado, pues los precios en el asiento variaban de acuerdo al estado momentáneo de aprovisionamiento del lugar, lo que convierte este informe como otros múltiples que aportan datos sobre precios en Potosí en testimonios de un valor muy relativo. ocasionados por la complejidad de acciones económicas y sociales en que estas mujeres comerciantes se vieron envueltas.

Hemos observado cómo los documentos nos las muestran acudiendo a la justicia en su propio nombre o como criadas de..., comprando grandes partidas de coca, por si mismas o por intermedio de sus propios criados, en casos de haber llegado a convertirse en comerciantes mayoristas, celebrando múltiples asientos y toda una serie movimientos para los cuales debieron de poseer completa libertad de acción.

Casos como por el cual Luysa criada de Contreras, comparece ante el juez de la villa, exigiendo que detengan a Myguel Moreno, por haberle sacado una yndia que le debía ciertos cestos de coca, a cuya causa el juez procede a encarcelar a Moreno, debiendose presentar el carpintero Francisco Ramírez como fiador del culpado, para garantizar que si despues de dos meses la india no volvía a pagar lo adeudado él se haria cargo del pago de los cestos de coca adeudados, debieron de surgir con cierta frecuencia (C.M.P., 1572, e. n. 4 , f. 29 y ss.).

Si nos detenemos ante los documentos testamentarios de las mujeres indias con que contamos, queda claro que en la gran mayoría de los casos ellas no llegaron a casarse con los padres europeos de sus hijos. La interrogante que surge aqui es si esto no fue más que el reflejo de un tipo de relacionamiento de mancebaje, peyorativo para estas mujeres y que comprueba la tesis que sostiene que las indias fueron espoliadas y violentadas sistemáticamente por sus conquistadores, o por lo contrario, fue una opción adoptada con el propósito de facilitar la actividad comercial de estas mujeres indias, evitando caer de esta manera en las redes que la institucionalización paternalista española del período les tenía tendidas.

En la medida en que los testimonios notariales son la formalización legal de acciones de orden civil, en esa misma medida no podemos pretender que estos documentos transgredan estas formas, por lo tanto, 
es posible sostener que en caso de que alguna de estas mujeres hubiera estado casada, gran parte de su actividad comercial en el asiento, sobre todo en caso de un desenvolvimiento económico superior, hubiera sido imposible.

De acuerdo al articulo LV de las Leyes de Toro, se determina que,

...la mujer durante su matrimonio sin licencia de su marido como no pueda hacer contracto alguno, asimismo no se pueda apartar ni desistir de ningun contracto que a ella toque, ni dar por quito a nadie del, ni pueda hacer quasi contracto, ni estar en juicio haciendo, ni defendiendo sin la dicha licencia de su marido:y si estuviere por si, o por su procurador, mandamos que no vala lo que hiciere (MARTÍNEZ ALCUBILLAS, 1885, p.725).

Por lo que una mujer no casada gozó de un grado muy superior de independencia de accion legal al de aquella que lo estaba, lo que en la realidad cotidiana de Potosí, se tradujo en uniones íntimas de corta duración, en que los hijos que fueron su resultado y que quedaron a cargo de la madre, rara vez fueron hermanos de padre, lo que de la misma manera aconteció en los casos en que fue el padre el que se hizo cargo de la crianza de sus hijos naturales.

De manera que posiblemente la causa principal porque fueron dictados estos testamentos fue la urgencia por dejar asentado el estatus de hijos naturales de sus vástagos, evitando así que siendo declarados ilegítimos o bastardos quedara impugnado su derecho a heredar los bienes maternos o paternos, tanto $a b$ testamento o ex testamento en caso de existir algun otro tipo de heredero legítimo.

De acuerdo al mismo Código en la ley XI, se establece que

porque no se pueda dudar quales son hijos naturales, ordenamos y mandamos que entonce se digan ser los hijos naturales, quando al tiempo que nascieron o fueron concebidos, sus padres podian casar con sus madres justamente sin dispensación:con tanto que el padre lo reconozca por su hijo. (MARTÍNEZ ALCUBILLAS, 1885, p.722)
Por esto la importancia en la testamentaria de las fórmulas por las cuales se adaptan los hechos a los requisitos legales, evidentemente la realidad debio de haber estado bastante alejada de este cuadro, pues los antecedentes conocidos para la población española demuestra el enorme número de casos de abandono de esposas en sus tierras de orígen, y en la misma medida podemos sostener que la opción por la procreación de hijos naturales estubo muy difundida entre los españoles que se establecieron en Indias, los quales en sus propios testamentos colocan junto a sus hijos naturales mestizos los abandonados en Europa.

De ahí que en la mayoría de los casos el que tomó la iniciativa para el dictado de un testamento debió de ser el mismo hijo heredero, interesado por dejar esclarecido su estatus legal, o también con el objeto de utilizar éste como arma en la lucha con sus medio hermanos por la herencia materna, ya hemos comprobado cómo no faltaron los vivos prestos a aprovecharse de algún feligres moribundo.

El caso de Ana Coricoca, natural de Pacaretambo, resulta esclarecedor al respecto, ella tuvo tres hijos varones, dos producto de su unión con Juan Gutierrez Bernal, llamados Juan y Diego, habiendo el último fallecido en edad temprana, y otro hijo con Pedro Guiral de Oviedo a quien se le llamó con su mismo nombre, el cual se encontraba en la ciudad de Cuzco al momento en que dictó su testamento.

Ana les ha dado cantidad de pesos y ha gastado en ellos en las cosas que le han pedido

...y a sido mi voluntad por mi quenta e hallado que no he agravado a ninguno en las dádivas que con ellos he hecho e porque en ningún tiempo entre ellos aya diferencias sino toda hermandad, amor y voluntad y el uno no pida ny diga al otro que fue agraviado.

La aparente preocupación que demuestra la madre por lo que pueda acontecer esta plenamente justificada pues este documento tiene la intención de separar al hijo menor ausente, de la herencia que el mayor opina que les dejó su padre a él y a su hermano 
fallecido. Ana describe a Juan como un buen hijo, pues se ha preocupado de cuidarla en sus enfermedades, alimentándome en su casa... a Pedro le da su bendición y le ordena que no venga contra estas clausulas...(C.M.P., 1587, esc.not. 12 f.1023 y ss.).

El desenlace de este drama no lo conocemos, pero posiblemente estemos frente al antecedente de alguna de las corrientes escaramuzas armadas de la tumultuosa historia de Potosí.

Intentando penetrar en la vida íntima de estas familias, podemos comprobar que en forma mayoritaria la crianza de los niños giró en torno a la madre, siendo ella la cabeza del hogar, sin embargo, casos inversos, en que el padre fue el que aglutinó a su alrededor a sus hijos engendrados en distintas mujeres, también existen. En ambos casos la preocupación por el bienestar y el futuro de estos niños resulta evidente.

Lo podemos comprobar en el caso de Alonso Hernández Perales, rico y poderoso potosino, - deja una herencia líquida de aproximadamente 83.111 pesos de plata ensayada -, crecida fortuna para un rico comerciante y dueño de minas en el asiento, incluso durante el período de bonanza y prosperidad vivido en las últimas décadas del siglo XVI.

En su testamento declaró tener cinco hijos naturales... que los tube con mujeres solteras con las quales pudiera contraer matrimonio sin dispensación..., sus edades comprendían entre los veinticinco años y los diez años de Sebastiana la menor. Deja claro que ...a todos los quales a cada uno dellos reconozco por ser mis hijos naturales. Procediendo despues a repartir sus bienes equitativamente sin distincion de sexo.

El afecto y cuidado por sus hijos lo hace patente en este documento, preocupándose incluso por el futuro de María niña, hermana de madre de su hija menor Sebastiana, a quien le deja doscientos ducados, para que sea yndoctrinada en la doctrina y pulicía de la dicha nuestra fee catolica (CM.P., 1589 , esc. not. 15 f. 527 y ss.).
Un caso parecido, en que los sentimientos de cariño surgen como el vínculo que unió a los miembros del grupo familiar, lo podemos observar en el caso de la rica Francisca Carna india, natural de Pilco, jurisdicción de la ciudad de Guánuco, ella tuvo dos hijas naturales, llamadas Ysabel Vázquez y Pacheco cuyo padre fue Juan Vázquez y Pacheco, y que al momento de dictar el testamento estaba casada con Alvaro Hidalgo, y Francisca Bermúdez cuyo padre había sido Cristobal Bermúdez, casada a su vez con Francisco Pareja.

En su testamento hace un recuento de los múltiples actos de cuidado y preocupación que ha tenido con ambas hijas, a las cuales les ha dado numerosos regalos durante su vida. Declara cómo cuando Francisca regresaba desde la ciudad del Cuzco junto a su marido, a instalarse permanentemente en Potosí, mandó a su otro yerno con una barra de plata a recibirlos al camino, porque se la dí para ayuda de las costas que hizieron en venir al pais...(C.M.P., 1588, esc. not. 13 f.121 y ss.).

Francisca es la mujer mas rica entre los testamentos que hemos estudiado, su comercio había traspasado los niveles del detalle para convertirse en una mujer que comerciaba coca a niveles mayoristas desde una tienda en la que al momento de dictar el documento tenía almacenados 100 cestos de coca para la venta.

$\mathrm{Su}$ fortuna comprendió varias propiedades y la posesión de barras de plata y otros bienes de alto valor, los cuales procedió a repartir entre sus dos hijas mestizas, a las cuales sin embargo, no nombra herederas de la tienda de coca de que fue propietaria.

Sus hijas siendo mestizas, estubieron excluidas de este comercio?, la respuesta a esta interrogante es afirmativa, la actividad comercial detallista de la coca debió de excluir a los mestizos, de la misma manera que estos fueron periódicamente excluídos del Gato o Tianguéz de Potosí.

Mujer de orígen modesto, ella no fue cuzqueña ni agregó el adjetivo de palla a su nombre, hace suponer que en la misma medida en que el grado de ladinización no fue de importancia para aumentar el nivel de desen- 
volvimiento económico que una mujer podía aspirar a alcanzar en Potosí, tampoco su orígen étnico jugó un papel significativo, lo que nos permite hacer una serie de observaciones referentes a la re-organización que vivió la población natural asentada a las faldas del Cerro Rico, y el tipo de familia que constituyeron.

Primeramente podemos constatar que la actividad comercial que desplegaron las mujeres coqueras las puso en contacto con un gran número de personas de las más variadas procedencias, el testamento de Magdalena Corvayache, por ejemplo, demuestra cómo la actividad cotidiana que una comerciante pequeña pero ya independiente desenvolvía el año 1572, le permitió relacionarse con indias residentes en las distintas parroquias de la villa, con su proveedor de coca y con un minero vendedor de objetos artesanales de plata (C.M.P., 1572, esc. not. 4 f.22 y ss.).

Los casamientos o uniones mixtas que se observan entre europeos e indígenas, se produjeron igualmente entre los mismos naturales, los cuales se unieron sin observar restricciones en relación al origen étnico de cada cual.

Los contratos y asientos de trabajo demuestran que en la mayoría de los matrimonios los miembros de la pareja fueron provenientes de ayllus o étnias distintas. Un fenómeno similar fue constatado en Quito durante este período por F. Salomon, quien llama la atención sobre el hecho que esta ciudad, se había convertido desde el punto de vista de la población indígena en un colluvies gentium ${ }^{8}$, o un sitio donde los matrimonios entre indígenas no observaron las limitaciones culturales prehispanas, produciendose una enorme confusión cultural y racial. En la Villa Imperial, el caso fue mucho mas radical que en Quito o en otra cualquier urbe colonial, pues la concentración po-

8 colluvies gentium $=$ confusión o barullo de gente, op.cit, F.Salomón 1988 p.339 blacional, que alcanzó niveles numéricos pocas veces antes observado incluso por los mismos colonos europeos, permitió que estos contactos se intensificaran todavía más.

Sin embargo la posibilidad de establecer que tanto para los indígenas como para los españoles, la gigantesca urbe se había convertido en una gran confusion humana, o en una Babilonia, esta fuera de nuestro alcance cognitivo, pues la documentación con que contamos, demuestra que las uniones multi-étnicas fueron una reacción espontánea de la población indígena frente a las formas de vida urbana, lo que comprueba un grado avanzado de capacidad de adaptación a las nuevas condicionantes, y que las expresiones de sorpresa negativas registradas por las fuentes hispanas provienen de españoles que consideraron que debían de ordenar las formas extravagantes de vida urbana que tenían ante sus ojos de acuerdo a un modelo europeo ${ }^{9}$.

Hemos comprobado asimismo cómo la relación con el español no fue el factor que les abrió a estas mujeres las puertas al éxito comercial, un europeo tuvo pocas probabilidades de influir en el funcionamiento interno del comercio minorista de la coca, el cual debía de desenvolverse exclusivamente entre indios para ser justo, al contrario, fueron estas mujeres encargadas de las tiendas de sus amos o empleadores, las cuales podían garantizar el éxito o el fracaso de

\footnotetext{
${ }^{9}$ Las constantes expresiones de asombro que registran las fuentes de orígen hispano referentes a Potosí, se tradujeron en una variedad de proyectos destinados a ordenar a la población que habitaba la villa de acuerdo a esquemas que permitieran darle una apariencia física que obedeciera a exigencias urbanas europeas. Estos proyectos nunca tuvieron éxito, uno de estos tuvo relación con las Parroquias de la villa, las cuales debían de albergar a sus feligreses de acuerdo al pueblo y a sus ayllus de orígen y que sin embargo nunca lograron a cumplir éste propósito, ver, B.N.M. mss. 3040 f. 167 y ss.
} 
sus negocios. Este hecho permite sostener que cuando las relaciones de yanaconaje o de trabajo entre europeos y mujeres indias se transformaron en relaciones personales, hasta el grado de la constitución de un núcleo familiar, debieron de estar basadas en sentimientos de orden afectivo.

El número de hijos que cada una de estas mujeres indias tuvo durante su vida fértil, fueron por lo general dos a tres formando familias pequeñas, en las cuales pudo estar presente el padre sin ser esto una regla, agregadas al hogar habitaron las criadas indigenas o las chinas, que las circundaron a medida que la mujer elevaba su nivel de riqueza.

La independencia económica que poseyó la mujer india en Potosí debió de influir enormemente en la forma como se desenvolvió su hogar.

La lengua en que se comunicaron los miembros de estos hogares fue la indígena o lengua de la tierra, aymará, quechua o puquina, en Potosí el español fue una lengua poco empleada, de acuerdo a los documentos notariales los lenguas estuvieron presentes en la mayoría de las transacciones comerciales y testamentos de estas indias, siendo los indios varones quienes aprendieron y adoptaron el español con mayor presteza.

Los primeros cronistas que visitaron el asiento describieron asombrados el mercado de Potosí, y colocaron a sus mujeres vendedoras como un factor de gran importancia y que les llamó la atención fuertemente, sin embargo, en la misma medida que surgieron intereses que impugnaron desde época temprana la estructura económica implantada en el lugar, en una proporción similar, el papel e incluso la presencia de estas mujeres fue puesta en tela de juicio y combatida.

El año 1549, el cronista Pedro Cieza de León, escribe uno de los primeros informes sobre el particular, contándonos cómo las más hermosas indias del Cuzco y de todo el reino se hallaban en este asiento... describiendo el enorme mercado, Gato o Tianguéz, con sorpresa y admiración, ...cosa extraña, y creo que ninguna feria del mundo se ygulo[sic] al trato de este mercado, relatando cómo,...muchos españoles enriquecieron en este asiento de Potosi con solamente tener dos o tres indias que les contrataran en este tianguéz..(CIEZA de LEÓN, 1986, p.293).

Entre los vaivenes económicos que se experimentaron durante este período no faltaron grupos de individuos interesados en transformar el régimen de producción del asiento y que embargados por fuertes prejuicios atacaron el sistema y también a las mujeres indias como parte integral de él, pintándolas con tintes marcadamente negativos. Estos ataques se sucedieron sobre todo en la década del 80' cuando se desenvuelve la discusión sobre el orígen del metal comerciado por los indios en el tianguéz, y que ya el virrey Toledo había hecho esfuerzos enérgicos por acallar.

De manera que el texto anteriormente citado de Cieza de León, se transforma en manos de estos corresponsales en la siguiente descripción sombría, que el licenciado Cepeda despacha al virrey Conde del Villar, (Fernando de Torres y Portugal, 1584-88),

...una india vendiendo coca en la plaza o gato que dizen y urtando al descubierto metales, como todos los yndios lo hazen da de comer y sustenta a un español y muchas a dos...,

los españoles vagabundos poseedores de los peores defectos,

...pasando su miserable vida en estos vicios y desventuras y con falsas esperanzas de porfas o pornefas tener plata se van a mas andar al infierno, como se puede presumir de muchos de ellos en quien no a bastado la predicación y rigurosas reprehensiones que les han hecho los religiosos de la Compañía de Jesús para apartarles de su mal vivir en que les a tomado la muerte en manos de las yndias amigas suyas.. (B.N.M., mss. 3040, f. 69v.).

Por su parte, Diego Rodríguez de Figueroa nos relata en su pequeño diario de la vida de Potosí en los días finales del año 1582, como, 
También hay muchos hurtos de los metales y se ofende en este cerro mucho a Dios nuestro señor porque van muchas yndias a el con pan, bino, pasas, confites a dar a los mineros porque les den alguna carga de metal y lo que es peor es que algunas yndias llevan aya a sus hijas doncellas y las venden a los mineros.(B.N.M., mss.3040, f.112).

Debió pasar mas de un siglo para que el único cronista potosino de nacimiento, a comienzos de 1700, nos cuente que las mujeres indias no solo fueron parte integral de la vida ciudadana de la villa, sino como Bartolomé Arzáns Orzúa y Vela no dudó en escribir, un grupo social positivo siempre preocupado del bienestar público y presto a ayudar al prójimo. (ARZÁNS de ORZÚA y VELA, T. II, p. 124, 148-149, 211).

Por último, si la historiografía actual las excluyó del sistema productivo del asiento, sin embargo los archivos regionales nos las imponen, planteándonos la urgencia de un estudio renovado de Potosí, con el objeto de acercarnos en toda su complejidad a los múltiples factores que participaron en su historia.

Posiblemente, la urgencia por dar una explicación a este malentendido nos vuelva a poner frente a las palabras con que el virrey Francisco de Toledo y otros muchos contemporáneos y entre ellos también el licenciado Juan de Matienzo, intentaron describir Potosí, dándose finalmente "por vencidos" como se declara este último en su obra el Gobierno del Peru, quien termina pidiendo disculpas porque,

Finalmente, es una confusion muy grande [Potosi], que hay pocos que lo entiendan:solo se entiende que lo mexor es en aquel asiento no hazer novedad (MATIENZO, 1967, p.133).

Apéndice Documental

Casa de Moneda de Potosi

Escrituras notariales 6 (1572)

f. 31

En el nombre de la Santísima Trinidad, sepan quantos esta carta de testamento vieren como yo, Catalina palla natural del Cuzco, otorgo e conozco que hago y hordeno Éste mi testamento por interpretación de Juan de la Peña, mestizo, y estando como estoy en mi sano juicio y entendimiento natural tal qual Dios mi
Señor fue servido de me dar y recabandome de la muerte natural, a todo hombre viviente e creyendo como creho en la Santa fe Catolica y en la Sta.Trinidad y en todo aquello que crehe y tiene la santa madre yglesia de roma hago y hordeno este mi testamento en la forma siguiente, primeramente

encomiendo mi anyma a mi Senor Jesucristo que la compro y redemyo por su preciosa sangre y ruego a nuestra senora la virgen Sta.Ma. y a todos los santos de la corte del cielo sean rogadores por mi ánima pecadora a mi Senor Jesucristo que me perdone mys pecados y quiera llevar mi anyma pecadora a mi senor Jesucristo que me perdone mys pecados y quiera llebar my anima a su santa gloria.

Ytem; declaro que soy natural del pueblo que se llama paullo ynga que es en el cuzco, y hija de huypollo mi madre y de gualpa coro mi padre.

Ytem; mando que mi cuerpo sea sepultado en el monasterio del señor santo domingo adonde gregorio de la peña mi amo le pareciere y que los clerigos y frayles que al dicho gregorio de la peña le pareciere acompañen mi cuerpo con la cruz de la yglesia mayor.

Ytem; declaro que yo soy cófrade de la cofradía de nuestra señora del rosario mando que los cofrades hermanos della me acompañen mi cuerpo como lo /f. 51v./ de acostumbre y mando que les paguen de mys bienes la limosna acostumbrada.

Ytem; declaro que las mysas y ofrendas que al dicho gregorio de la peña le pereciere que se digan y ofrendan por mi ánima se digan y ofrescan.

Ytem; declaro que no debo cosa alguna que al presente se me acuerde.

Deudas.

Ytem; declaro que debe una yndia colla que llama Urcomo que reside en la doctrina de santo domingo tres pesos y medio de coca y pan que le bendí.

Ytem; declaro que me debe una yndia que se llama aguallo que reside en la Rancheria que la conocen los de casa._ _la qual me debe seis pesos de plata corriente de pan que le bendí.

Ytem; declaro que me debe una yndia que se llama tocta que reside en la doctrina de san francisco doce pesos corrientes de pan que le bendí.

Ytem; declaro que me debe Diego yndio, mi hermano dos pesos y medio corrientes.-

Ytem; declaro que me debe quicana yndia dos pesos y medio de pan y coca-_

Bienes. 
Ytem; declaro que tengo en mi caja cinquanta pesos de plata corriente.

Ytem; declaro que tengo tres piezas de ropa de cumbe nuebas

Ytem; declaro que tengo quatro pieza de ropa de abasca biejas e nuebas, las quales mando se de y repartan entre mis hijas./f. 52/

Ytem; declaro que gregorio de a peña mi amo me hizo donación[y a mis hijas] de estas casas y corrales que al presente moro para que durante los dias de mi vida [y de las de mis hijas]viviese en ellas e las tubiese e gozase dellas como de cosa mia propia./digo y declaro que las dichas casas y corrales de que ansi me tiene hecha la dicha donación después de los días de mi bida son del dicho gregorio de la peña y de las dichas mis hijas y de juan de la peña hijo del dicho gregorio de la peña y en esto me rremito a la dicha donación la qual se guarde y cumpla como y de la manera y con las condiciones que el dicho gregorio de la peña mi amo nos la hizo.

Ytem; declaro que yo ube una hija que se llama maria de balencia en pedro de balencia de arequipa y es su hija del dicho pedro de balencia la qual obe siendo soltera y el dicho pedro de balencia soltero, mando que si el dicho su padre la quisiere llebar se la de el gregorio de la peña.

Ytem; declaro que yo hube una hija en el dicho gregorio de la peña mi amo que se llama francisca mestiza de hedad de catorce anos la qual obe siendo muger soltera y el dicho gregorio de la pena soltero y por tal mi hija y del dicho gregorio de la peña declaro ser mía.

Ytem; dejo y nombro por mis albaceas y testamentarios al

\section{Fuentes Primarias}

ARCHIVO GENERAL DE INDIAS (A.G.I.) Justicia 667 ARCHIVO NACIONAL DE BOLIVIA (A.N.B.) Actas del Cabildo de Potosí, T.8; Escrituras Públicas, Bravo, 1569 BIBLIOTECA NACIONAL DE MADRID (B.N.M.) mss.3040 CASA DE MONEDA DE POTOSI (C.M.P.) Escrituras Notariales $4,6,12,13,15$.

CAPOCHE, Luis (1585) Relación de la Villa Imperial de Potosí, Biblioteca de Autores Españoles, Madrid, 1959. dicho gregorio de la peña mi amo al qual doi todo mi poder complido libre llano bastante segun lo tengo y de derecho mas pueda baler para que entre y tome todos mys bienes judicial y extrajudicialmente y/o como bien bisto le fuere y los benda y remate en pública almoneda y en su balor cumpla este my testamento y lo que mando y ansi complido y pagado dejo y nombro por /f. $52 \mathrm{v} . /$ mis herederos universales en los demas bienes remanescientes a la dicha francisca hija del dicho gregorio de a peña y mía y a juan de la peña hijo del dicho gregorio de la peña para que ambos a dos juntamente por yguales partes tanto el uno como el otro y al otro como al otro por yguales partes los [hereden] y a la dicha maria de balencia le mando de mys bienes cincuenta pesos de plata corriente para ayuda de su casamiento y con esto la parte de todos mys bienes y herencia

Ytem; mando a las mandas forzosas medio peso de plata corriente a todas ellas y con esto las aparto del derecho que puede tener a mys bienes.

Ytem; reboco y anulo y doi por ninguno y de nyngun balor otro qualquier testamento o testamentos que haya hecho por escrito o por palabra que quiero que no balga salbo este que al presente hago y hordeno que quiero que balga por mi codescilio $\mathrm{y} / \mathrm{o} /$ testamento e por my ultima e perpetua boluntad o como mejor lugar a derecho a lugar que fue fecho y otorgada en la villa ymperial de potosi trece dias del mes de setienbre del ano de myll e quinientos y setenta e dos, a nos, siendo presentes por testigos rogados y llamados Juan barba, pedro lopez, diego lópez de jara e myguel de vidauri, e andres marín estantes en esta dicha villa y por que la dicha otorgante no sabia firmar la firmo de su nombre a ruego de la otorgante Juan barba

\section{Antemi Martín de Barrientos}

CIEZA de LEÓN, Pedro (1553) Crónica del Perú, $1^{a}$ parte, Pontificia Universidad Católica del Perú, 1986 COLECCION LEGISLATIVA DE MINAS t.1 Madrid, 1889.

ENCINAS, Diego de (1596) Cedulario Indiano, Ed.Cultura Hispana, Madrid, 1945.

MATIENZO, Juan de (1567) Gobierno del Perú, Institut D‘etudes Andines Paris-Lima, 1967. 


\section{Bibliografia Secundaria Selecta}

BAKEWELL, Peter Mineros de la Montaña Roja, el trabajo de los indios en Potosí.1545-1650. Alianza Madrid, 1989.

BURKETT, C.Elinor "Indian Women and White Society: the case of sixteenth-century Perú"; en Latin AmericanWomen, ed. A.Lavrín, Greenwood Press England, 1978.

DAUMARD, A. FURET, F. "Les Archives Notariales et Mecanographie", en Annales 1, p.676-693, 1959.

GOODY, Jack "Women, Class and Family" en New Left Review, 219, p.119-132, 1996.

KLAPISCH-ZUBER, Christiane "Les Femmes et la Famille" en

L'Homme Medieval, ed. Jacques Le Goff, Editions du Seuil, p.315343, 1989.

KOWALESKI, Maryanne "Women's Work in a Market Town: Exeter in the Late Fourteenth Century" en Women and Work in Preindustrial Europe, Ed. Barbara A. Hanawalt, Indiana University Press, 1986.

LAVRÍN, Asunción "Women in Spanish American Colonial Society" en The Cambridge History of Latin America, vol.II, ed. Leslie Bethell, $1^{\text {a }}$ ed, 1984.

LAVRÍN, A. \& COUTURIER, E. "Dowriws and Wills: a view of women's socioeconomic role in colonial Guadalajara and Puebla 1640-1790", en Hispanic American Historical Review 50, 2, p.280-304, 1979.

LEVILLIER, Roberto Gobernantes de Perú, cartas y papeles del s. XVI, ed.Jun Pueyrredón, vol.VIII, Madrid, 1924.
LOCKHART, James El Mundo Hispanoperuano, 1532-1560, $1^{\mathrm{a}}$ ed. Española, Fondo de Cultura Económica, 1982.

MARTÍNEZ ALCUBILlA, Marcelo Códigos Antiguos de España, Madrid, 1885.

MARTÍNEZ GIJÓN, José "El Régimen Económico del Matrimonio y el Proceso de Redacción de los Textos de la Familia del Fuero de Cuenca" en Anuario de Historia del Derecho Español vol.XXIX, p.45-151, 1959.

MÖRNER, Magnus "Economic Factors and Stratification in Colonial Spanish America with Regard to Elites" en Hispanic American Historical Review, 63, 2, p.335-369, 1983.

OPITZ, Claudia “Life in the Late Middle Ages" en The History of the Women in the West. Harvard University Press, vol.2, p.267-317, 1992.

OTS, José María “El Sexo como circunstancia modificativa de la capacidad jurídica en nuestra legislación de Indias" en Anuario de Historia del Derecho Español vol. VII, p.311380, 1930.

OTERO, Alfonso "La Patria Potestad en el Derecho Histórico Español" en Anuario de Historia del Derecho Español, vol.XXVI, p.209-241, 1956.

PETIT, Eugene Tratado Elemental de Derecho Romano, tr. J.Fernandez Gonzales, ed.Alabatros, Buenos Aires, 1972.

SALOMON, Frank "Indian Women of Early Colonial Quito, as seen through their testaments" en The Americas 3, p.325-345, 1988. 